\title{
NT-Pro BNP Predicts Acute Left Ventricular Failure Patients with Acute Myocardial Infarction: A Prospective Study
}

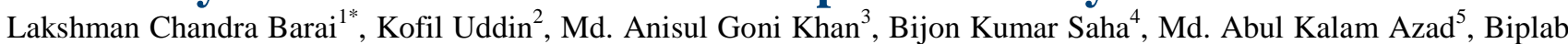
Kumar Das ${ }^{6}$

\footnotetext{
${ }^{1}$ Assistant Professor, Cardiology, MBBS, D.CARD, MCPS, National Institute of Cardiovascular Diseases and Hospital, Dhaka, Bangladesh

${ }^{2}$ Assistant Registrar, MBBS, MD, National Institute of Cardiovascular Diseases and Hospital, Dhaka, Bangladesh

${ }^{3}$ Consultant, MBBS, MD (Cardiology), National Institute of Cardiovascular Diseases and Hospital, Dhaka, Bangladesh

${ }^{4}$ Assistant Registrar, MBBS, D.CARD, National Institute of Cardiovascular Diseases and Hospital, Dhaka, Bangladesh

${ }^{5}$ Medical Officer (Cardiology), MBBS, D.CARD, National Institute of Cardiovascular Diseases and Hospital, Dhaka, Bangladesh

${ }^{6}$ Assistant Professor, MD, Cardiology, Sheikh Sayera Khatun Medical College, Gopalganj, Bangladesh
}

DOI: $10.36347 /$ sasjs.2020.v06i01.001

| Received: 30.12.2019 | Accepted: 07.01.2020 | Published: 17.01.2020

*Corresponding author: Lakshman Chandra Barai

\section{Abstract}

Background: Mortality risk is quite variable among fibrinolytic treated ST elevation myocardial infarction patients. Careful and early risk evaluation of each patient is therefore important. Until now, the most evaluated biomarker has been troponin I on admission, which gives strong prognostic information. NT pro BNP has shown reasonable promise in predicting the adverse outcome of STEMI. This research will provide the information regarding its efficacy as a predictor of adverse outcome following STEMI. Objective: To assess the prognostic value of N-terminal pro-brain natriuretic peptide in fibrinolytic treated ST elevation myocardial infarction (STEMI) patients. Method: This short term prospective study was done in Cardiology Dept. of National Institute of Cardiovascular Diseases and Hospital, Dhaka, Bangladesh. We valuated 115 patients of STEMI admitted within 12 hours and receiving thrombolytic therapy. Venous blood sample was collected for NT pro BNP before starting fibrinolytic therapy. Additional clinical data was recorded including detailed complications of STEMI. Results: Out of 115 patients of STEMI 50.5\% patient had adverse outcome among them $9.6 \%$ patients died, heart failure $31.3 \%$, cardiogenic shock $7.8 \%$, VT \& VF 5.2\%, acute MR $2.6 \%$, VSR $0.9 \%$, CHB $2.6 \%$ and $49.5 \%$ patient had no adverse outcome. According to association between hospital outcomes with N-terminal pro BNP level, it was observed that the mean N-terminal pro BNP level was higher in adverse outcome group. Based on the receiver-operator characteristic (ROC) curves N-Terminal Pro BNP level gave a cut off value $\geq 480.0 \mathrm{pg} / \mathrm{ml}$, with $88.5 \%$ sensitivity and $100.0 \%$ specificity for prediction of complications and similarly N-terminal pro BNP level gave a cut off value $\geq 725.5 \mathrm{pg} / \mathrm{ml}$, with $72.7 \%$ sensitivity and $93.3 \%$ specificity for prediction of mortality. Conclusion: N-Terminal Pro BNP level was highly sensitive and very much effective in the evaluation of adverse outcome of fibrinolytic treated ST elevation myocardial infarction (STEMI).

Keywords: STEMI, NT- pro BNP, Outcome of STEMI.

Copyright @ 2020: This is an open-access article distributed under the terms of the Creative Commons Attribution license which permits unrestricted use, distribution, and reproduction in any medium for non-commercial use (NonCommercial, or CC-BY-NC) provided the original author and source are credited.

\section{INTRODUCTION}

Coronary artery disease (CAD) is predicted to be the most common cause of death and disability globally by 2020 [1]. Acute myocardial infarction patients increasing in our country and remain a leading cause of morbidity and mortality. Careful and early risk evaluation of each patient is therefore important. Until now, the most evaluated biomarker has been troponin I on admission, which gives strong prognostic information. NT-pro BNP levels rise soon after the onset of symptoms in patients with ACS and this may help to risk stratify patients early in the course of the disease [2]. NT pro BNP has shown reasonable promise in predicting the adverse outcome of STEMI. This research will provide the information regarding its efficacy as a predictor of adverse outcome following STEMI. The results if satisfactory may be adopted as practice guideline and regular investigation marker for early risk stratification and prognostic information. Identification of high risk patients with high NT proBNP on admission in STEMI may be helpful for selection of more intense interventional or pharmacological treatment strategies. Early tissue level reperfusion is especially important in patients with raised NT pro BNP concentration and can alter the adverse outcome for this high risk group. 


\section{METHODS}

This prospective study was carried out in the Department of Cardiology, National Institute of Cardiovascular Diseases and Hospital, Dhaka, Bangladesh from January 2019 to October 2019. We evaluated 115 patients of STEMI admitted within 12 hours onset of chest pain which lasted for at least 30 minutes and receiving thrombolytic therapy. STEMI was diagnosed when ECG showing ST elevation of 1 $\mathrm{mm}$ or more in two or more contiguous leads except v2v3 where 2 or $>2 \mathrm{~mm}$ of ST elevation in men with age more than 40 years, $>2.5 \mathrm{~mm}$ with age $<40$ years and $>$ $1.5 \mathrm{~mm}$ in women. Patients with STEMI with delayed arrival more than twelve hours, preexisting Heart Failure, NYHA III and IV functional classes, serum Creatinine $>2.5 \mathrm{mg} / \mathrm{dl}$ were excluded from the study. Informed consent was obtained prior to any studyrelated procedures. Demographic data and prevalence of risk factors was obtained from all patients. Detailed clinical history and physical examination was done. Venous blood sample was collected for NT pro BNP before starting fibrinolytic therapy. NT pro BNP was determined by sandwich immunoassay on an Elecsys 1010 (Roche Diagnostics). Additional clinical data was recorded include a detailed description of complications encountered during hospital stay such as ventricular arrhythmia, complete heart block, cardiac failure, cardiogenic shock, other complications of STEMI and death.

\section{STATISTICAL ANALYSIS}

Statistical analyses were carried out by using the Statistical Package for Social Sciences version 20.0 for Windows (SPSS Inc., Chicago, Illinois, USA). A descriptive analysis was performed for all data. The quantitative and qualitative observations were indicated by frequencies and percentages. Chi-Square test was used to analyze the categorical variables was shown with cross tabulation and unpaired t-test was used to analyze the continuous variable was expressed as mean $( \pm \mathrm{SD})$. Receiver operating characteristic (ROC) curves was generated to determine the cutoff values for the best sensitivity, specificity for prediction of mortality and complication. A P-value will considered to be statistically significant if $\leq 0.05$.

\section{RESULTS AND OBSERVATIONS}

This study was total number 115 patients with STEMI, out of them 93 patients were male and male to female ratio was 4.2:1. Majority $52(45.2 \%)$ patients were in $5^{\text {th }}$ decade. Mean age was found $58.7 \pm 11.0$ years in adverse outcome group and $50.04 \pm 8.9$ years in no adverse outcome group. There were statistically significant $(p<0.05)$ between two groups except result of smoking and Diabetes mellitus which was not statistically significant $(\mathrm{p}>0.05)$ between two groups (Table-1). Regarding in hospital outcome, patient with adverse outcome group had high $\mathrm{N}$-terminal pro BNP level than no adverse outcome group (Table-2). Based on the receiver-operator characteristic (ROC) curves in this series it was observed that N-Terminal Pro BNP level had area under curve 1.000 , which gave a cut off value e"480.0 pg/ ml, with $88.5 \%$ sensitivity and $100.0 \%$ specificity for prediction of complications. Similarly based on the receiver-operator characteristic (ROC) curves N-Terminal Pro BNP level had area under curve 0.963 , which gave a cut off value $\geq 725$ $\mathrm{pg} / \mathrm{ml}$, with $72.7 \%$ sensitivity and $93.3 \%$ specificity for prediction of mortality.

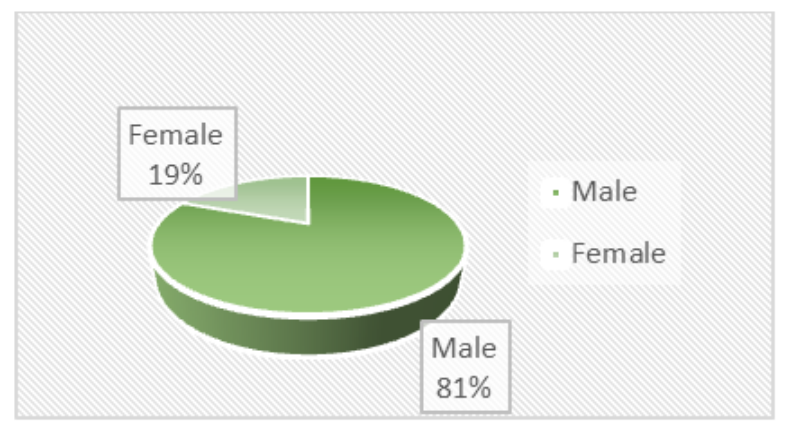

Fig-1: Sex distribution of STEMI patients

Table-1: Association of demographic data and CVD risk factors with outcome among the study population $(n=115)$

\begin{tabular}{|c|c|c|c|c|c|c|}
\hline \multirow[t]{3}{*}{ Characteristics Age (years) Mean \pm SD } & \multirow[t]{3}{*}{ Total } & \multirow{2}{*}{\multicolumn{2}{|c|}{$\begin{array}{l}\begin{array}{l}\text { Adverse outcome } \\
(\mathrm{n}=37)\end{array} \\
\mathbf{5 8 . 7} \pm \mathbf{1 1 . 0} \\
\end{array}$}} & \multirow{2}{*}{\multicolumn{2}{|c|}{$\begin{array}{l}\begin{array}{l}\text { No adverse outcome } \\
(n=78)\end{array} \\
50.04 \pm 8.9 \\
\end{array}$}} & \multirow{3}{*}{$\begin{array}{l}\mathbf{P} \\
\text { value } \\
{ }^{\mathrm{a}} 0.001^{\mathrm{s}} \\
\end{array}$} \\
\hline & & & & & & \\
\hline & & $\mathbf{n}$ & $\%$ & $\mathbf{n}$ & $\%$ & \\
\hline \multicolumn{7}{|l|}{ Sex } \\
\hline Male & 93 & 34 & 91.9 & 59 & 75.6 & ${ }^{b} 0.038^{\mathrm{s}}$ \\
\hline Female & 22 & 3 & 8.1 & 19 & 24.4 & \\
\hline Smoking & $61(53 \%)$ & 21 & 56.8 & 40 & 51.3 & ${ }^{\mathrm{b}} 0.582^{\mathrm{ns}}$ \\
\hline Hypertension & $63(54 \%)$ & 28 & 75.7 & 35 & 44.9 & ${ }^{\mathrm{b}} 0.001^{\mathrm{s}}$ \\
\hline Diabetes mellitus & $53(46 \%)$ & 21 & 56.8 & 32 & 41.0 & ${ }^{\mathrm{b}} 0.113^{\mathrm{ns}}$ \\
\hline Dyslipidemia & $67(58 \%)$ & 37 & 100.0 & 30 & 38.4 & ${ }^{\mathrm{b}} 0.001^{\mathrm{s}}$ \\
\hline $\begin{array}{l}\text { Family history of } \\
\text { premature CAD }\end{array}$ & $23(20 \%)$ & 13 & 35.1 & 10 & 12.8 & ${ }^{\mathrm{b}} 0.005^{\mathrm{s}}$ \\
\hline
\end{tabular}

$\mathrm{s}=$ significant $\mathrm{n}=$ not significant

${ }^{\mathrm{a}} \mathrm{P}$ value reached from unpaired t-test

${ }^{\mathrm{b}} \mathrm{P}$ value reached from chi square test 
Table-2: Association of hospital outcome with N-terminal Pro BNP level $(n=115)$

\begin{tabular}{|l|l|l|l|l|}
\hline Hospital outcome & \multicolumn{2}{|l|}{ N-terminal pro BNP level (pg/ml) } \\
\hline Heart failure & N & Mean SD & \multicolumn{2}{|c|}{ Min - max } \\
\hline Cardiogenic shock & 36 & $990.0 \pm 51.8$ & 430 & -570 \\
\hline VT\&VF & 9 & $723.0 \pm 90.3$ & 610 & -870 \\
\hline Acute MR & 6 & $770.0 \pm 56.4$ & 720 & -880 \\
\hline VSR & 3 & $736.7 \pm 40.4$ & 690 & -760 \\
\hline CHB & 1 & $715.0 \pm-$ & 715 & -715 \\
\hline Death & 3 & $760.0 \pm 26.09$ & 731 & -780 \\
\hline No adverse outcome & 11 & $779.3 \pm 67.8$ & 720 & -880 \\
\hline
\end{tabular}

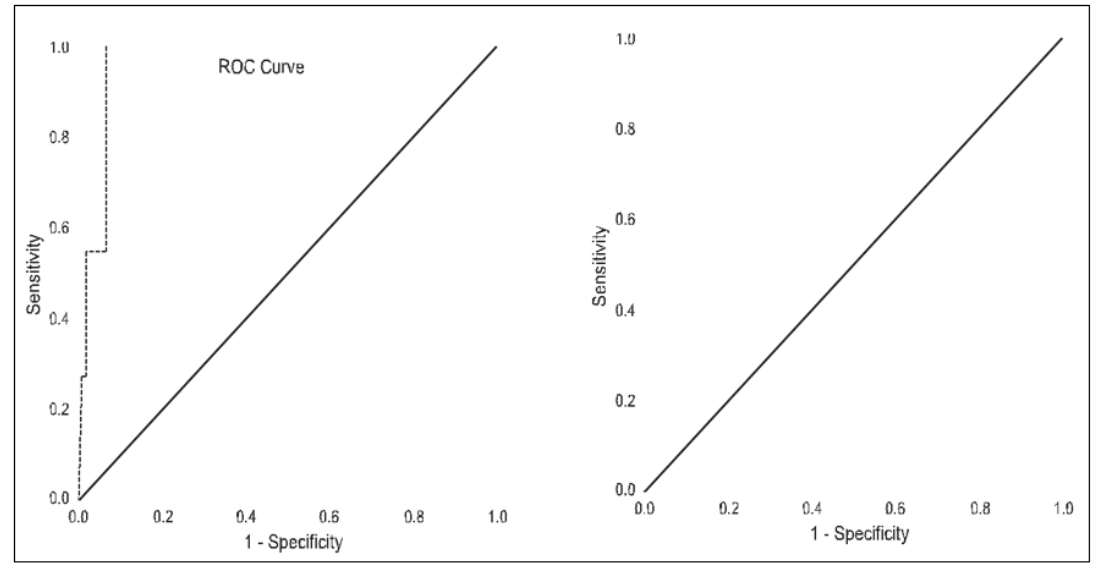

Fig-2: Receiver-operator characteristic curve of N- Terminal Pro BNP level for prediction of mortality and complication

Table-3: Receiver-operator characteristic (ROC) curve of N-Terminal Pro BNP level for prediction of mortality $(\mathbf{n}=\mathbf{1 1 5})$

\begin{tabular}{|l|l|l|l|l|l|l|}
\hline $\begin{array}{l}\text { N-Terminal Pro } \\
\text { BNP level }\end{array}$ & Cut of value & Sensitivity & Specificity & \multicolumn{2}{|l|}{$\begin{array}{l}\text { Area under the } \\
\text { ROC curve }\end{array}$} & \multicolumn{2}{|c|}{ 95\% Confidence interval (CI) } \\
\cline { 4 - 6 } & & & & Lower bound & Upper bound \\
\cline { 2 - 6 } & $\geq 725.5$ & 72.7 & 93.3 & 0.963 & 0.930 & 0.996 \\
\hline
\end{tabular}

Table-4: Receiver-operator characteristic (ROC) curve of N-Terminal Pro BNP level for prediction of complications $(\mathbf{n}=\mathbf{1 1 5})$

\begin{tabular}{|c|c|c|c|c|c|c|}
\hline \multirow{3}{*}{$\begin{array}{l}\text { N-Terminal Pro } \\
\text { BNP level }\end{array}$} & \multirow[t]{2}{*}{ Cut of value } & \multirow[t]{2}{*}{ Sensitivity } & \multirow[t]{2}{*}{ Specificity } & \multirow{2}{*}{$\begin{array}{l}\text { Area under the } \\
\text { ROC curve }\end{array}$} & \multicolumn{2}{|c|}{$95 \%$ Confidence interval $(\mathrm{CI})$} \\
\hline & & & & & Lower bound & Upper bound \\
\hline & $>480.0$ & 88.5 & 100.0 & 1.000 & 1.000 & 1.000 \\
\hline
\end{tabular}

Table-1 shows association of characteristics and outcome of the patients. Mean age was found $58.7 \pm 11.0$ years in adverse outcome group. All other result was statistically significant $(\mathrm{p}<0.05)$ between two groups except result of smoking and Diabetes mellitus which was not statistically significant $(p>0.05)$. Table-2 shows association of hospital outcome with N-terminal pro BNP level. It was observed that patient with adverse outcome group had high N-terminal pro BNP level than no adverse outcome group.

\section{DISCUSSION}

In this present series it was observed that out of one hundred fifteen patients $50.5 \%$ patient had adverse outcome among them $9.6 \%$ patients died, heart failure $31.3 \%$, cardiogenic shock $7.8 \%$, VT \& VF $5.2 \%$, acute MR $2.6 \%$, VSR $0.9 \%$, CHB $2.6 \%$ and $49.5 \%$ patient had no adverse outcome. Galvani et al., mentioned in their report that out of one hundred thirteen patients $6.4 \%$ died within 30 days [3]. In another study Ezekowitz et al., found $6.0 \%$ deaths, $6.3 \%$ with cardiogenic shock, $0.3 \%$ stroke and $6.6 \%$ with new-onset heart failure. In our study mortality was a bit more than other relevant study [4]. According to association between hospital outcomes with $\mathrm{N}$-terminal pro BNP level, it was observed in this present series that the mean $\mathrm{N}$-terminal pro BNP level was higher in adverse outcome group. Similarly patients who had an event had a significantly higher median NT-pro BNP compared with those who remained event-free $(\mathrm{P}<0.05)$ reported by previous several authors such as Galvani et al., 2004; Bjorklund et al., 2006; Ezekowitz et al., 2006; Michael Weber et al., 2008 [3-6]. The mechanisms potentially responsible for the strong association between NT-pro BNP elevations and shortterm mortality cannot be ascertained by the present study. However, BNP and NT-pro BNP release may be triggered by transient or permanent ventricular 
dysfunction induced by myocardial ischemia [7]. Moreover, the magnitude of the increase may reflect the extent of the ischemic injury, elevations being detected soon after the onset of myocardial ischemia [8, 9]. We measured NT-pro BNP after the onset of ischemic symptoms. Such early increases may reflect the amount of the ischemic insult to the myocardium rather than the of actual extent myocardial necrosis. Accordingly the prognostic accuracy of NT-pro BNP was suggesting that NT-pro BNP may be considered as an early ischemic marker. In this present study it was observed that based on the receiver-operator characteristic (ROC) curves N-Terminal Pro BNP level had area under curve 0.963 , which gave a cut off value $\geq 725 \mathrm{pg} / \mathrm{ml}$, with $72.7 \%$ sensitivity and $93.3 \%$ specificity for prediction of mortality. Similarly, Based on the receiver-operator characteristic (ROC) curves in this series it was observed that N-Terminal Pro BNP level had area under curve 1.000 , which gave a cut off value $\geq 480.0 \mathrm{pg} / \mathrm{ml}$, with $88.5 \%$ sensitivity and $100.0 \%$ specificity for prediction of complications. Michael Weber et al., obtained in their study that receiver-operating characteristics curve analysis yielded an optimal cutoff value of $474 \mathrm{pg} / \mathrm{ml}$ for NT-pro BNP that was able to discriminate patients at higher risk [6]. In receiver operating characteristic analysis Bjorklund et al., showed NT pro BNP strongly associated with mortality (area under the curve $0.81,95 \%$ confidence interval (CI) 0.72 to $0.9,0.67,95 \%$ CI 0.56 to 0.79 , and 0.66 , $95 \%$ CI 0.56 to 0.77 , respectively), which is closely resembled with the present study [5]. The present study is the first one to demonstrate that a single measurement of NT-pro BNP, obtained on admission, provides important prognostic information of STEMI patients. In this study, we have demonstrated that the early measurement of NT-pro BNP provides important information for risk stratification of STEMI. To the best of our knowledge, this is the first time that elevations of NT-pro BNP early after symptom onset are shown to have a profound and independent impact on short-term mortality in STEMI patients. Such findings may have important implications for immediate management of high-risk patients with STEMI. Our results, obtained at the earliest time from symptom onset. In particular, they confirm the prognostic value of natriuretic peptides even in patients without heart failure as detected by patient history or at initial evaluation.

\section{CONCLUSION}

N-Terminal Pro BNP level was highly sensitive and very much effective in the evaluation of adverse outcome of fibrinolytic treated ST elevation myocardial infarction (STEMI).We have demonstrated that higher N-Terminal Pro BNP level is associated with not only higher complication but also mortality in STEMI patients. So it can be concluded that NTerminal Pro BNP level is a useful prognostic value to detect the hospital outcome of ST elevation myocardial infarction (STEMI) patients.

\section{LIMITATIONS}

Although the result of this study supports the hypothesis there are some facts to be considered which might affect the results. Results were not correlated with other confounding variables. Further study in required for long term follow up.

\section{REFERENCES}

1. Murray CJ, Lopez AD. Alternative projections of mortality and disability by cause 1990-2020. Global Burden of Disease Study. Lancet, 1997; 349: 1498-504.

2. Jernberg T, Stridsberg M, Venge P. N-terminal pro brain natriuretic peptide on admission for early risk stratification of patients with chest pain and no ST-segment elevation. Journal Am Coll Cardiol, 2002; 40: 437-45.

3. Galvani M, Ottani F, Oltrona L, Ardissino D, Gensini GF, Maggioni AP. 'N-Terminal Pro-Brain Natriuretic Peptide on Admission Has Prognostic Value Across the Whole Spectrum of Acute Coronary Syndromes. Circulation, 2004; 110: 12834.

4. Ezekowitz JA, Théroux P, Chang, W, Mahaffey $\mathrm{KW}$, Granger CB, Weaver WD. N-terminal probrain natriuretic peptide and the timing, extent and mortality in ST elevation myocardial infarction. Can Journal Cardiol, 2006; 22(5): 393-97.

5. Bjorklund, E, Jernberg, T, Johanson, P, Venge, P, Dellborg, M, Wallentin, L. 'Admission N-terminal pro-brain natriuretic peptide and its interaction with admission troponin $\mathrm{T}$ and ST segment resolution for early risk stratification in ST elevation myocardial infarction', Heart, 2006; 92: 735-40.

6. Michael W, Oscar-Bazzino JL, Navarro E, Juan JF, Fernando B. 'N-Terminal B-Type Natriuretic Peptide Assessment Provides Incremental Prognostic Information in Patients with Acute Coronary Syndromes and Normal Troponin $\mathrm{T}$ Values upon Admission. Journal of the American college of Cardiology, 2008; 51(12): 1188-95.

7. Omland T, Persson A, Ng L. 'N-terminal pro-Btype natriuretic peptide and long-term mortality in acute coronary syndromes' Circulation, 2002; 106(29): 13-18.

8. Tateishi J, Masutani M, Ohyanagi M. 'Transient increase in plasma brain (B-type) natriuretic peptide after percutaneous transluminal coronary angioplasty. Clinical Cardiol, 2000; 23, 776-80.

9. Kyriakides ZS, Markianos M, Michalis L. 'Brain natriuretic peptide increases acutely and much more prominently than atrial natriuretic peptide during coronary angioplasty. Clinical Cardiol, 2000; 23:285-88. 